\title{
“BRIGHT FUTURE?" THE KNOWLEDGE, PRACTICES AND STRATEGIES OF THE YOUNG PEOPLE IN A SOUTH SIBERIAN EVENKI VILLAGE ${ }^{1}$
}

\author{
István Sántha
}

\begin{abstract}
The article deals with young people's ideas, activities and lifestyles in an Evenki village in Southern Siberia, interprets the differences of the value orders of generations in the narratives and practices in the context of the local, surrounding the society and Russia in general.

Through research into youth we can get a more wholesome picture of the community. Furthermore, after the collapse of the Soviet Union the future of a society depends more and more on the new intelligentsia, the members of which have not grown up in the Soviet period. The young people living in the taiga, the edge of the civilized world, share the activities of their parents: that is, they hold on to their roots while the authorities persuade them to leave their village. The responses of the youth in relation to the desires and the possibilities are more openminded, and in these opinions the social expectations of these young people are less conformist. Different generations have different value orders. The events which have not happened in the life of young individuals do not serve as a standing-ground in life, and the activities of everyday life and the ideas are intertwined, and become the lifestyles of different generations.
\end{abstract}

Key words: gender, hunter-gatherers, Siberia, socialization, stereotypes, taiga forest, youth

\section{INTRODUCTION}

The village is forty kilometres away from the high voltage power line and the highway to the district, or raion centre. These two symbolise the "civilization". A journey by truck from the village in the taiga to the first village along the road to the district centre takes approximately four hours in wintertime. From the end of April until the beginning of November, depending on the ecological situation and weather, the village is inaccessible by truck because of mud. During this period it can only be reached on used army trucks or cross-country vehicles (vezdekhody) or (as it often happened in the past) by helicopters. These machines and fuel is available on the will of district administration. Helicop- 
ters have not flown to the village except in dental (or other medical) emergencies and in summertime the aeroplanes of firemen brigades work in the taiga fighting fires.

Major power lines do not reach the village. One old communal diesel engine generates electricity for the local people. "Normally", when there is fuel in the village the club is open every day from 5 PM till 1 AM in summer and from $8 \mathrm{PM}$ to $1 \mathrm{AM}$ in winter. In 2003 fuel ran out already by June. During this period there was no electricity in the village except for two days for preparation procedures of a funeral. Besides the communal one there were three privately owned diesel engines in the village (one of which was out of order), working with private fuel, which was used to illuminate the houses of returned male family members, leaving an odd, contrastive impression of the rest of the village in the evening dark. During the dark nights villagers used to drink, and when electricity was available, people turned to television and had less time to drink.

\section{NOTES ON THE METHODS AND LIMITATIONS OF THE ANALYSIS}

\section{Overview}

The present paper deals with the activities, lifestyles and ideas of young people in an Evenki village in Southern Siberia, and their relation to the adult community. It is based on fieldwork conducted from September to November in 2003 among Upper-Lena Evenki, who have settled in a predominantly Evenki village in the central part of Irkutsk Oblast. For comparison I have used the material collected by me among the different Evenki (Tungus and Orochen) groups living east and west of Lake Baikal in 1995, 1999 and during my recent field research in Baunt district, Eastern Buryatia among the Orochen Evenki in $2004 .^{2}$

In the past 15 years, writing academic papers about the Russian society in English has become quite fashionable, because it enables scholars to succesfully conduct research into youth in transition (changing) societies (see Trommsdorff 1994, Kasurinen 2000: 122). These studies not only discuss the aspects of gender, ${ }^{3}$ but also those of generations, which generally applies to studies on young people (Riordan 1989, Pilkington 1994). Most authors of these studies are sociologists and the approach is sociological. The first articles published in English show the influence of articles written in Russian at that time (Semashko \& 
Sedlovskaia 1999, Pushkareva 2003), because most of the research was carried out in the framework of international cooperation between Western and Russian scholars (Williams 1999); furthermore, the aim of some of these researchers was to juxtapose the Western world and the Russian society. This is evidenced by the problem of availability of Western theories in the context of Russian society; such as the studies based on the comparision of Karelian youth in Russia and the neighbouring territories of Finland (Puuronen et al. 2000).

In general, it can be established that youth research is based on Western theoretical traditions and aim at understanding the very recent developments in the Russian society. ${ }^{4}$ At the same time, the studies probably have some impact on the Russian society: the fact that they are dealt with may leave the impression of stability to the members of the society, bring the young people in Russia closer to youth all over the world, and Russia to the Western world, and also integrate Russian youth into Russian society. There are also some studies on youth with more concrete theoretical interests, for example on everyday life, ${ }^{5}$ or cultural globalization (global and local). In anthropological studies, materials collected at participant observations have been used next to questionnaires and semi-structured interviews. This new scholarly trend in Siberian anthropology was also shown at international conferences on youth in Halle, Germany in November $2003^{6}$ and in Tartu, Estonia in October 2004. ${ }^{7}$

Currently there is a growing trend to conduct anthropological research in regions of the former Soviet Union. These research works are of special significance because less and less people follow the traditional (economic) ways of life as a result of external (not local) interests and influences, which remain a legacy of the Soviet period. The settled groups of the 'small peoples of the North' become increasingly isolated from their traditional value orders. After the collapse of the Soviet Union, future has come to depend on a new generation of intelligentsia ${ }^{8}$ which was born in the 1990s and which members have not grown up in the Soviet Union.

The society's future perspectives are related to the youth. Observation of only the adult society will leave a more constant, inflexible picture. However, if the perspectives of youth are added to the picture, the general view will be much more dynamic because relations between age and gender cohorts will be more marked. One of the most important features of the studies into youth today is the wider perspective of time, ${ }^{9}$ and its main purpose is to understand the general characteristics of the society as a whole. This will give a nuanced picture of the society and allows making some general considerations. 


\section{Fieldwork methods}

My interest towards adults determined the nature of my questions to youth. First, I sought to determine the differences between the opinions of adults and youth. Second, I tried to explain the reasons of these differences in the context of local, neighbouring, and Russian societies. Third, I tried to analyse the future society on the basis of these differences.

Two main methods were used during my fieldwork. Participant observation $^{10}$ introduced me the activities of the youth, while semi-structured interviews informed of their ideas. In terms of interpretation, this means that the material did not enable me to get a general overview about youth, because my work did not entirely focus on the young. Nevertheless the fieldwork provided on the one hand a more comprehensive picture of the village society in general, and, on the other hand, a more relative one from the reflexions of young people to "the world of adults" (according to my interpretation).

The subject group of my study no longer attended school (in the village or elsewhere). All members of the group lived permanently in the village, in parental homes, and were aged between 15 and 23 .

\section{Activities of the youth}

In the following, various activities and their significance to the young people's identity, how these activities are divided between the genders, and how young people talk about these activities, will be discussed. My impressions about this topic are derived from participant observation. Young men participate in all events of social life. They usually do most of the common work. The young work for their parents and learn what they have to do by imitating the older generation, but have no say in decision-making. The most important role of youth is that they function as a mirror to their parents and thus give them a chance of self-control.

At the edge of the civilized world (and Russia), the Evenki youth living in the taiga are engaged in the same activities as their parents. It is difficult to say what options are available for them, except, perhaps, the one preferred by the district administration - to leave their village forever. With the depopulation of the village, which has recently begun, its territory may become available for the neighbouring Russians and visiting hunters from Irkutsk. At the same time, the disappearance of the village may solve for good the almost unresolvable problem of the inaccesibility of the village for the most part of the year. 


\section{Diverging values}

Conversations with the younger members of the subject group were very halting and hesitant; one of the most important features of them being uncertainty. The answers of the older youth were generally more specific, and the responses to questions about adults and estimating their possibilities were rather critical. While the responses of the youth were more straightforward, those of their parents corresponded more with social expectations and habits. $^{11}$

I have come across opinions of young people from another Evenki group who say that to understand the knowledge of older generations means to know what to leave aside in practice, because it can be overlooked in everyday life. It indicates that different generations have different value orders.

The responses reflect the different values of adults (in the context of folk legends) and youth (practical life). ${ }^{12}$ The verbal knowledge of older generations generally does not function as a basis of norms for the youth. ${ }^{13}$ The events that have not happened in the lives of the young people (stories about the past are only narratives for them), do not play any role in their everyday life; they can only get the knowledge based on these past narratives in the course of socialization. At the same time the narratives of the past do not influence the youth when forming opinions.

\section{Lifestyles}

As shown above, there are certain themes in which some ideas and practices of the young and adults differ, while others are quite similar. The activities of everyday life and the ideas are intertwined, and become the lifestyles of generations. Ethnic identity and drinking alcohol are fine examples (stereotypes) of the different practices and ideas. I would like to analyse these three topics in the framework of case studies because each of them has a long tradition and at the same time has had relevance in recent times all over Russia.

\section{RESEARCH QUESTIONS}

My questions about youth were based on my main research interests in a wider context about the elders. I was interested in the attitudes of the intraethnic Evenki groups towards each other and their categorization (designation and 
self-designation) on the basis of different economic activities. I attempted to study interethnic marriages among Russians. What role do the similar mixed patterns (examples) play in the choice of sexual and marriage partners?

In my research I attempted to find answers to the following questions:

- What do young people think about their present life and what connection do their opinions have with the ideas of the older generations?

- How do young people interpret their future perspectives?

- Which options can youth choose from when they do not want to lead the same life as their parents?

My questions to the young people concerned ethnic identity, living in the village and leaving it (by coercion of external power), and also, the relevance of traditional activities such as hunting in the taiga. In the light of outside stereotypes and local reactions to these, I have to mention drinking alcohol and sexuality. Furthermore I was interested in what a "closed" world, a world far away from civilization means in modern Siberia. ${ }^{14}$ There were two more general research quests behind the thematic surface of these themes: solidarity, gender, and generation. These were not (only) my personal interests but the central research topics in the Siberian Studies Centre in Halle.

During my research I was also interested in the additional topics of the youth - military service, life in the club, attending school - and further details of ethnicities, such as interpretation of prestige and future perspectives. However, these aspects were more descriptive and at the same time the differences in discussing these topics by youth and adults were not that significant. ${ }^{15}$

There are three stages in the activities of the local people: the village, the taiga, and the neighbouring villages with the district centre. The meeting point of these stages and the focal point of my research interest was the village.

There were three common themes in the fieldwork (ethnic identity, alcohol consumption, and sexuality), and all of these concerned the village. At first sight, these topics were not considered important in the taiga. Furthermore, there are the outsiders' and local stereotypes and ideas about them; my experiences are derived from participant observation. Until today, these stereotypes are valid all over Russia, and there are very deeply engrained Russian stereotypes connected to 'the small peoples of the North'.

Ethnicity and, internally, interethnic identity is the main focus of research about the peoples living in the Baikal region, and next to alcohol consumption and sexuality as themes of research, my aim has been to find the connection between outsiders' stereotypes and the recent situation in this aspect on the basis of participant observation. 
“Bright Future?” The Knowledge, Practices and Strategies of the Young People...

\section{GENDER ROLES IN HUNTING}

Nowadays, nomadism is a practice of men's seasonal activities, which has been simplified in many ways. While men travel to distant territories for longer or shorter periods of time, women (with very few exceptions) remain in the village throughout the year. The lifestyle of men is no longer completely nomadic although whenever necessary they still use old nomadic methods, mainly during hunting and fishing. In this way the nomadic pastoral families have become seasonal hunting-fishing-gathering and partly sedentary people.

In the village and the taiga, ethnic identity is of no special importance on the first level (locality), whereas on the second level (of authority and administration), only Evenkis are allowed to take guns from the territorial group or obshchina. Almost every man has his own hunting territory on the obshchina, and the grounds were allocated at the beginning of the 1990s. This is usually important during the fur-hunting season. In modern times, common law predominates in many ways. All local people are freely allowed to hunt (large) wild animals (except for sables and squirrels) and fish. Only the few whose forefathers had lived on the territory of the present obshchina can claim their own ancient (familial) hunting grounds, because most of the local Evenki began to settle in the village from far away during the collectivization and after the first buildings were constructed in $1930 .^{16}$

Hunting is thus youth's main activity. There are very few men who do not go to the taiga during the hunting season, and there are some women who accompany their husbands; also there is a woman who goes hunting on her own. No woman can lead a normal life without a hunter husband, except for teachers who are paid and supported by the district administration. All the boys and girls agreed that without hunting living in the village would be impossible. In the girls' interpretations, the boys were hunters and fishermen and, consequently, the "normal" men in the village. This approach has an economic as well as a social aspect: hunting is just as indispensable as men. It is believed that women (except for those who work as teachers) cannot do without men. Hunting also signifies the integration of boys into the adult society. It is particulary important for the boys, but also for the girls, because hunting is an essential aspect of being an adult man. From this moment on boys become potential sexual partners in the interaction of boys and girls.

Girls' life goes on in the village, and their entire knowledge is related to this stage. They only visit the taiga when accompanied by boys but not, for example, by their parents. Girls never see the hunting places, because going to the taiga is, generally speaking, only an excursion to 'nature'. These last 
two aspects revealed that the level of solidarity and autonomous cooperation among the members of a generation is much higher (on the basis of friendship or companionship ${ }^{17}$ ) than among family members, with whom people are in hierarchic (complementary / kinship) relations.

The boys' knowledge is related to life in the taiga, but in general only to the family hunting places. In the interviews, the boys described the taiga as their home which is associated with freedom. While for youth the taiga represents the sense of nature and home, for the young men, living in taiga represents freedom from wife. Neither the girls nor the boys defined the idea of obshchina, because it is not their responsibility. It is, however, important for them as it makes hunting possible.

The young men practically never hunt alone; they always hunt together with male relatives because they do not have their own hunting territories; that is, no separate housholds are associated with them. The boys hunt for themselves, which basically means that their family sells their furs. One function of hunting together is to help the father, but at the same time it is a challenge for the young man to test himself, a way to emphasize one's virility. When hunting in the taiga, all men are equal. The Russians are no worse than the Evenki, at least according to the accounts of the boys. Adult men and youth agreed that ethnic identity is of no importance in the taiga.

\section{LIFE IN THE VILLAGE AND THE TAIGA IN THE EYES OF THE YOUNG PEOPLE}

The young people live like their parents in many ways. In the absence of other ways to pass time, they spend more time on fishing and preparations for hunting, help their relatives and neighbours, relax, but do not attend school. It is a general view that life in the village and in the taiga is very hard, and it is easier to live outside the village, on the territory of obshchina. At present, ethnic identity is defined by one's birth (place), which is closely related to the place of growing up, because members of this generation already have been born in the district centre. This situation (marked by the place of birth, the village) also has a temporal aspect, which is manifest in the feeling of homesickness after living in the "outside world"18 for three months.

For the younger youth, living in the village is a more sensible and interesting idea. One of the older youths spoke about the village as the place connected with their relatives and friends. Another youth spoke negatively about 
his home, "In the outside world we cannot find work, but here at home we can find the same activity as the parents." These ideas create some distance between the home and the outside world: home is perceived from the perspective of living outside the village. They visit home as if they were guests for a very short time. The position of these young people in the village is temporary. Other young respondents associated 'living here' with the idea of the 'establishment of their own family'.

Friendship ${ }^{19}$ implicitly has played a very important role in the social life of the village (among youth and adults), which is defined by the youth on the basis of solidarity, "who respects me is respected by me". ${ }^{20}$ The general idea is not to hurt anybody. It is an attempt to maintain peace among the individuals. House, as the place where the individuals live, does limit the range - that is, young people usually choose their friends from amongst the youth of the neighbouring families. Inside the territory of the village with 250 inhabitants, there are some borders which are unsurpassable in reality. While the boys choose friends in the neighbourhood, the girls choose friends from amongst classmates, that is, their own generation. Different ethnic background is not important among friends. The different parts of the village (for example, old village, hospital, schoolyard, lower village, and the new part) are organized in accordance with the period and the group the inhabitants settled in from. It is strongly associated with ethnicity. Even if it is not verbalized and emphasized, this situation has not changed until now, at least on the practical level.

\section{LIVING IN THE VILLAGE OR LEAVING IT}

Today, unlike in the second half of the 1980s and the first half of the $1990 \mathrm{~s}$, almost everybody outside the village - district administration (see 1 in the list below), gas companies (2a), environmentalists (2b), even some former Evenki inhabitants - migrated to Evenkia (3) and elsewhere (4) instigates the local people to leave their village. At the end of 2003, there were three main questions which concerned the near or distant future of the village, and all of them originated in the outside world.

1. The district administration supports those who intend to move out of the village in several aspects. It coincides with the plans of many locals, especially women and girls. The administration prompts the Evenki (even forces the villagers), especially youth, to leave their territories by buying them houses in the surrounding Russian or Buryat villages. The authorities wish to execute it 
with the money from the state for the 'small peoples of the North', which is intermediated to the locals through them.

2. (2a) This policy is connected with the gas pipeline that was to be built across the territory of Upper-Lena Evenki toward China. Others who were interested in their land made them to recognize its value.

(2b) The Upper-Lena Evenki have understood that if their lands are important for the outsiders (hunters and builders of the gas pipeline and enviromental activists - to establish natural parks and in this way protect the land from the ecnomic interests), the land must be important for themselves.

3. Another outside interest was propagated even by some former Evenki inhabitants of the village who moved to gain ethnic privileges in Evenkia (Tura and Baikit; jobs given to people of Evenki ethnicity, free accommodation of children in boarding schools (Internat) and free education of children in secondary schools and institutes). From this aspect it is the Evenki ethnic identity that is emphasized. On the occasion of visiting the village, the local Evenki were invited by their relatives to move to Evenkia because it is easy for the Evenki to find a job there - at least according to the interpretation of village inhabitants. Even so, the prestige of these visiting relatives from Evenkia is ambiguous, because they describe the remaining Evenki as uncivilized, which is percieved also by the local Evenki. This is why the local people received them as guests and not as relatives. Furthermore, none of those who had left the village returned to live there again. ${ }^{21}$

Almost all the habitants of the village, except for the elders and the children speak about leaving the village at least in the form of an idea or daydream; however, nobody knows when it may really happen. While all the girls think about leaving the village, the boys only contemplate it when they are ready to get married. It does not depend on whether the potential wife is local or comes from outside village. ${ }^{22}$ The main concern regarding people's staying in the village or living outside is money. In the village, cash is not used..$^{23}$ Without cash the people cannot travel; for example, parents cannot visit their daughters who lived along the road to the district centre.

Another important aspect was closely related to the first one - namely, work. This a highly problematic issue because of the very high unemployment rate also in the surrounding villages. The older boys were more sceptical about finding a job outside the village, while the younger ones and the girls were confident about finding work there. A defining aspect was also the place where the relatives and the friends were living outside the village. All the young people understood that for people from the taiga, getting help outside the vil- 
lage was possible only for a short period of time. Remarkably, some people gave vague answers to the question concerning their last visits to the neighbouring villages. For some young people, visiting the neighbouring villages is merely an idea, because they have never left the village. The reasons for that is perhaps the lack of financial means of their families. Furthermore, while questioning youth I have come to understand that communication between the village and the outside world is as indispensible as air in everyday life. They manage to communicate with the outside world through the members of their generation who have left the village to study, and thus learn about the opportunities outside. Otherwise, the parents make decisions about the children's education depending on their means.

The boys are more mobile not only in terms of the taiga but also the outside world. Some of them cannot predict their future life in five years' time; the only thing that they can be certain of is that they will not remain in the village but will be living in Irkutsk. The plans depend on individual experiences, and the collective knowledge of previous generations is not important for them.

Even though hunting is an essential criterion for being a man, some boys do not hesitate to give it up for something like working in the centre, because for them hunting is only a seasonal activity (see also Ziker 2002: 29-63). There is no contradiction in this, because hunting skills may facilitate finding work in the district centre. Also, both occupations meet the expectations of the girls. The boys whose mothers have come from outside the village have more chances of finding a wife from the outside world, but at the same time they believe that their future wives might move to the village, as their mothers once did. The girls are motivated to leave the village because they do not like the local boys, as many have a drinking problem. Also, among the local boys, there exists a negative stereotype about the girls who smoke and do not remain faithful. The similar thinking of the girls and their mothers becomes evident also in the fact that their mothers prefer to leave the village with their daughters. If the girls leave the village, they would come back to see their mothers. Buying a house in the framework of the 'small peoples of the North' programme is also problematic, because the potential buyers live in the taiga whereas the sellers live in the village centre. Also, the buyers have no spare time or financial possibilities to go to the village centre and carry out the transaction. During my visit, two families wished to leave the village and one left. Obviously, the people who intend to leave are those who have the clearest picture about the future.

In sum, if the life of the village is approached from the aspect of gender and generations, a certain divergence between the responses of parents and children becomes evident: children tend to have no idea as to the plans their parents may have with them. Sometimes it may be due to the gender gap: 
parents cannot agree upon their child's future and this may be confusing for their children.

While fathers tend to approve the boys' staying in the village, and the safety makes them prefer the taiga, mothers - especially those of Russian background likely support their daughters' moving to the village.

Although youth take their parents' life as a model for their future, most of them still take any opportunity to leave the village and try to make it in the outside world. The experiences of the older generations show that part of youth who leave the village come back only when they want to settle down and have a family.

\section{ALCOHOL}

A young man once called me out of the house where I stayed, and asked for some money to buy vodka. On another occasion, some young men turned to our house to drink, but at the sight of my bewilderment they asked me to sell them alcohol for money. It was unexpected for me, because according to my fieldwork experience in Siberia in the past 15 years, the permanent drinking had only been characteristic for people aged 20 or older.

Drinking is one of the few decisive aspects in the general life of the village. All the different generations: old people, adults and youth, regardless of their gender, and even children during their school years, can be seen drinking. Interestingly, there is one stereotype spread all over Russia and North America about the drinking of native peoples. These peoples who have no practice and tradition of drinking alcohol, an enzyme ( $\mathrm{ADH}$ or alcohol dehydrogenase) is lacking in their bodies to cope with alcohol in their blood. There are peoples who can manage their drinking (Russians and, for example, Buryats, whereas the latter make alcohol from fermented cow milk) because they have consumed alcohol already some centuries ago, and there are others who cannot manage their drinking. The latter get drunk very quickly (and this is harmful for others and themselves). All the people in Siberia (Russians and indigenous peoples, and also Evenki) believe that this is a definite fact. However, I approach this "fact" as a stereotype because I have never come across any scientific evidence to this problem. So it is a very ambivalent situation. When visiting the village, Russians always take alcohol along. Some Evenkis in the village explain that their relation to alcohol is that the Evenki people are ill, they are really different, they cannot drink as much as the Russians, and consenquently they have a right to drink without any regard to quantity or quality: it is the illness that makes them drink all the alcohol, regardless of its 
quality. In their narratives, these people emphasize that uncontrolled drinking is an ethnic characteristic of the Evenki: "We can not help it, we are Evenki people; it is in our blood". Other Evenki, however, interpret this as a sure sign of alcoholism.

There are three topics that have a very close connection with the permanent alcohol consumption among the adult population. First, the Evenki language is spoken almost only during drinking alcohol. ${ }^{24}$ Second, on these occasions people start to tell legends about their ancestors. Its function is to remember and express the level of ethnic identity connected with these legends through the personal stories. Third, the local knowledge on shamans in most cases also means the remembering of the past through individual (life) stories. Today, people talk about shamanism while drinking alcohol only in the taiga.

What do the opinions of the young people in the village reveal about the drinking? It is very common to think that drinking is something negative. According to the opinions of youth, alcohol consumption is a very topical problem. All the young people (boys and girls alike) drink, but few speak openly about their own drinking. Younger respondents agree that young men are expected to drink like adults only after they have passed the military service. Youth start drinking on the example of adults (the significant difference is that the young people do not smoke).

Although answers to the question whether natives drink more than outsiders is very ambiguous, the practice of drinking is important. Locals, especially those who are unmarried, drink because they cannot find work. Most young people think that their drinking is less of a problem than in other families. At the same time there were some older respondents (boys as well as girls) who emphasized that drinking depended only on personality, and not on whether one lives in the village or elsewhere. It is part of the indidual's life (and responsibility).

In terms of alcohol there appears to be certain solidarity among the local people (they do not tell on each other) although it is not as strong as in the case of sexual behaviour. The manner of caution during conversations with outsiders, which is characteristic of these narratives is fascinating, which emphasizes their knowledge about the (outsider) stereotypes related to drinking (further on this see the section about sexuality).

While speaking about occasional drinking, a young hunter mentioned that it ensured good hunting luck, but the girls did not believe this association. Youth do not think that they can change the adults' drinking habits.

During the extended drinking bouts of adults, youth carry out the daily activities of adults with full responsibility, even if only for a short time. It is also part of the socialization of the young people in the village. 
The drinking of adults gives a rhythm to village life, and so do television programmes when there is electricity. The adults and youth drink at the same time but separately, in different places. Groups of youngsters from the same families drink together (as is the case with adults). The adults' group gathers in one house while their sons and daughters in another, always strictly separated. Youth do not participate in the drinking of the adults because the usual aggression among the adults (interethnic conflicts determined by historical verbal legends) poses a big threat. These types of conflict do not happen during the drinking sessions of the youth.

Drinking with friends is a matter of responsibility. A little while before my stay, an accident happened at a local party: a young man froze to death because his friends were not responsible enough to look after him..$^{25}$

Nevertheless, adults are generally not aggressive towards the youth; on the contrary, they are kind to them. Even so, they buy alcohol with the money they should spend on their children (their food and clothes). The young think that when drinking the adults do not care about their children. It is quite a common phenomenon among the Evenkis, and also in other Evenki communities, that they irresponsibly lose control while drinking. So, the adults and youth drink separately.

The opinions of youth as expressed in the verbal narratives seem to be the same as those of adults. The materials based on participant observation remain inadequate when seeking an answer to the question what happens when the young men drink alcohol among themselves. Are there any conflicts, and if so, with what are these connected? There probably is an important divergence in the answers of adults and youth. While ethnicity is not a key question among youth, it is important for the adults, although the latter deny it during the interviews.

A further question is what happens to youth when they become adults. The examples of the age group (20 to 25) show that those who already have formed a family are very quickly socialized into the practical life of adults, at the occasions of drinking alcohol with the elders. Further questions arise concerning the above. What role do the values of youth play in contrast with those of adults? How important is the value order of youth in their later life? Is it more important for them to determine what their partners drink than it is with their parents? Is it only a recent tendency or the generation problem?

The prevailing opinion in the village is that adults drink everything, regardless of the quality of alcohol or the company - what matters is drinking as such. Casual attitude is one of the main features of drinking. It is the characteristic element during the initial stage when people choose their drinking partners, but later (after the second day) this is no longer important. 
This casual attitude is not characteristic of youth drinking, because, first of all, it is illegal for boys before the military service and girls before the birth of their first child to drink alcohol. Otherwise, all the people know about this, and parents put up with the youth's drinking: they are not able to control it, since the young only drink when the adults do the same. The loss of control by adults conditions the drinking of youth.

At the same time, the difference in drinking is that youth always control their situation and more carefully choose their drinking partners. There can not be ethnic conflicts between them on the grounds of misunderstanding, lack of knowledge, or injury.

\section{INTIMACY}

Nighttime equals with intimacy and it has quite an important, private, and secret role in the life of youth. Despite the absence of light (that is, electricity) on Saturday evenings, the girls get dressed and go to the house of a young single mother with a three-year-old son to meet the boys. The house is located near the schoolyard where the woman worked. This is a relatively new phenomenon: only half a year before previous habitants had been forced to move out of the house and leave the village by the district administration. In the house, one room is occupied by the family, while the other is permanently available for organizing parties for youth over 18. Boys qualify as youths only after serving in the Russian Army. This status is valued among the young men, because it is the symbol of adulthood for the young women. The youth play cards, listen to music (when there is electricity) and drink alcohol. Procuring alcohol is not a problem either, because some of these boys' relatives trade with alcohol. Younger boys meet on the street, next to the schoolyard, near a building shared by the local administration, library, and two families. Young people aged about 14 to 17 smoke and drink, while hiding on the street.

Next to alcoholism, there is another stereotype in literature about the 'small peoples of the North', which also exists as a narrative for the Russians living in the neighbourhood, and is known also by the local people. According to this stereotype, the local women are available for visitors in the village, who believe that the women find sex advantageous. A stereotype of Russians tells about the need for "fresh blood" (that is, healthy descendants) in the closed community.

People, in general, do not speak about sexual life, especially with strangers. Before I knew almost nothing about this topic, I had only observed the connection between the habits of drinking alcohol and sexual behaviour, but 
the young men did not tell much about it. Even though sexuality is not an individual narrative theme, the opinions of adults certainly correlated with those of the young people. The young emphasized the different views of the local people and visitors ('non-locals'), which at the same time stresses the importance of locality, and shows, though not openly, the solidarity of the local people and the exclusion of outsiders. The strangers may have practical knowledge about sexuality, but they have no idea about the local people's narratives concerning this subject. So, sexuality is taboo not only in practice but also in verbal comments. It is not a conversation topic in the village among the young or the adults.

\section{'LOCAL' OR 'STRANGER'}

This distinction correlates with the dynamic manifestation of ethnic identity. In most cases, the local people employ the distinction in a rather controversial manner. People sometimes also make a difference between a stranger and a guest. The attitudes towards strangers are often gender-based. Young men, in general, have a more unique attitude as they see strangers as rivals; they think they can eliminate possible rivals by stigmatizing them as strangers. Boys tend to make a more sharp distinction between outsiders and locals when it came to men, because of the hunting territories (on identity see also Ventsel 2005).

The girls' attitude towards teachers (who are women and strangers) ${ }^{26}$ is even more exceptional than that of boys. Girls regard female teachers as their rivals. "The teachers are 'others' (Russian: "Oni - ne nashi"), because they haven't grown up here". ${ }^{27}$ According to the general opinion, only the teachers remain outsiders for the local people: they live in the village and cannot change their status, but their children can already become locals if they grew up and stayed in the village.

The Evenki people who have moved to the North, Evenkia, can become guests, but only in the village where they were born. Their relatives interpret it as follows: they speak "as if they have never lived here". ${ }^{28}$

\section{ETHNIC IDENTITY}

While discussing the Evenki culture, the headmistress of the local school (who has a mixed Cherkes-Russian ethnic background) asked me as a scholar studying the Evenki to help her choose the best time to hold an Evenki feast. 
I suggested November 7 as the biggest "Evenki" holiday, because this is the time when every hunter returns from the taiga to the village to sell furs and rest. However, she did not support my idea, because she thought that a truly significant day would have a different, more traditional and original purpose. This intention was in connection with her aim to create a more spectacular form of local shamanism, because when she had last visited Irkutsk with a local school ensemble, this was a popular trend among the 'small peoples of the North' in Irkutsk oblast.

There is a small museum in the school building next to the offices of the headmistress and teachers. Here the female teachers with Russian background had collected different objects of the everyday life of Evenkis (from the relatives of their Evenki husbands). They had superfically labelled the objects as shamanic even though the local traditions did not confirm their ideas. The next day, after my remark these objects had disappeared from the wall of the school museum and only the captions on paper reminded of the former presence of the objects illustrating local shamanism.

Different stereotypes exist about the Evenki ethnic identity and their status as the 'small peoples of the North'. In the Soviet times, the Evenki, as an ethnic group, were thought to be on the verge of disappearing.

The second stereotype is that of a sniper of Evenki background in the Soviet (Russian) Army, which is based on the prestige and practices of young taiga hunters, who are excellent shooters. Being an Evenki can be important for military officers as the continuation of the Soviet tradition rooted in the Second World War (for example, on the basis of the plot of the novel Trubka snaipera ['The Sniper's Pipe'], Irkutsk 1980), though not for other soldiers. I think that the manifestation of ethnic identity is important for the Evenki men themselves (for individual reasons), because this way they can identify themselves with their home region, and be attached to it. Being homesick while serving in the Russian Army evokes in the soldiers the feeling of ethnic belonging, of 'being Evenki'.

Today the practice of mixed marriages is common in the village. I know only one Evenki family, who has no Russian blood; however, local Evenki nationalists also proclaim to be the only family in the village who is of "pure" Evenki descent. Before the Second World War, the region was occupied only by the Evenki. Russians (and others) started to migrate to the village only after 1944. The process of Russians and other newcomers becoming Evenki is easily traceable. As the first step they settled in the village, but they could only stay there by marrying the locals. Becoming an Evenki was important for the outsiders because this was the only way to get access to the hunting grounds. All the descendants have become Evenki, regardless of whether it was their mother 
or father who had an Evenki background. The only exception was those who grew up outside the village. In this case, the ethnic significance of this outside milieu and and not the ethnicity of relatives played a decisive role in choosing relatives for their children's ethnicity. Otherwise, the parents (that is, mothers) registered their children as Evenki because of free education, meals, and clothes which were donated to the 'small peoples of the North'. Although these privileges were no longer available after 1995, the parents nonetheless registered their children as Evenki in village statistics (pokhoziaistvennye knigi, 'household records') in hope of the return of the good old times.

The present form of interethnic categorization is the differentiation between the established locals and newcomers. To this day, the female teachers of the local school form the majority of newcomers. They can stay and integrate into the village community only if they marry Evenki men, by which way they become mothers of Evenki children.

For adults, the officially registered (absolute) ethnic identity is not important in the village; it is rather the symbiosis and the habitual (local) aspects that are emphasized. The dynamics of ethnic identities in the village shifts towards uniformity: all the families sooner or later become Evenki. But the everyday practice of drinking alcohol day after day strengthens the (relative) ethnic differences of the community members. On these occasions, interethnic tensions, conflicts and violence easily emerge. In these cases participants tend to define their ethnic identity on the basis of others. Thus, ethnic identity is the most important for the adult when they are intoxicated (in an "altered" state of mind); and they talk about it unwillingly, as if they have to, as if it was a reflex.

So, while in the context of the legends and narratives there are more interethnic polarization and exclusion (and the ethnic value judgements are more violent), in everyday life there is more inclusion and tolerance, and the adoption of other norms is considered valuable.

While in everyday life the people from mixed families easily change their ethnic identity in accordance with their personal interests and depending on what plans they have for the future (to live in the village or leave the village, to become the head of the obshchina, etc.). In the context of legends, however, the values are stable.

For the young people, ethnicity is natsiia, natsional'nost'. There are individuals of different ethnic background, but this fact does not play a major role in the social life in the village (either among youth or adults). There is a context (of ethnic legends) among the adults which can be observed during drinking alcohol. This context is not activated among the young people when they drink. 
But there is another distinction between the strangers and locals which is quite important here. The term 'local' does not only mark the place of birth but it also includes those who have grown up here (the role of socialization). Each person has an ethnicity which does not depend on his or her individual personality. Ethnicity depends on what other people think about the individual. According to the local categorization, the Evenki and Russians are grouped together, but in the opinion of boys of Evenki background, the Evenki and Russian ethnicities correlate with the identities of 'locals' and 'strangers' ${ }^{29}$ It does not play any major role if somebody is Evenki or Russian in everyday village life, but it makes sense that the ethnic identity can be altered from the outside perspective if it happens to be more advantageous.

The patterns of ideas about ethnicity are given by parents. This has not appeared on either the individual or the very broad social level, but rather on the level of the family's practices, ideas, and opinions. These play a decisive role in the young people's ethnic identifications.

At the same time, it is often not important for the outsiders to make the distinction whether young people (e.g., from Tuturi) are Evenki or not. These cases also emphasize the solidarity between the young.

It is difficult to say anything very general about about the importance of the ethnic background of a future life partner for the youth; this is an ambiguous or a much more complex issue than can be analyzed here. While most of the narratives reveal that ethnic identity has no importance, some girls prefer to have metis ('of mixed ethnicity') or russkii ('Russian') partners and can not imagine having Buryat or other Evenki partners. Contrary to the opinions of adults, the girls think that the ethnicity of a child depends more on the child's father will than the mother's.

Next to traditional ethnic designations (Evenki, Buryat, Russian), there are new ones existing in the village. The metis category does not exist among the adults, but is quite important among youth. Sometimes it is connected with the lack of or insufficient knowledge about the others' ethnic background. Or, for example, in the case of the interethnic marriages the parents define their children as metis. In my opinion the process of becoming metis has a connection with the cases when the interviewee preferred not to specify his or her own mixed ethnicity.

Sometimes a young man identifies himself as metis on the basis of the existence of other, purely ethnic people, especially the Evenki. But it is also true that from the point of view of those who are pure metis, all the others will once ultimately become the same, Evenki. ${ }^{30}$

For most people in the Evenki village it is very important and prestigious to be Evenki, while it is less emphasized among youth. Parents and all the rela- 
tives are perceived as Evenki, although there is no way of knowing the exact details of their Evenki ethnic background. Friends are also Evenki. The behaviour among the Evenki is 'normal' (Russian: normal'no 'friendly'). There are Evenki not only from this village but from two other villages as well. It was also clear by the fact the young Evenki did not make any distinction among themselves on the basis of locality. ${ }^{31}$

According to the interviewees' responses, Russians were initially considered 'strangers' (they came, settled down, obtained a territory and hunted, in the historical context), but then became 'locals'. They liked being there (in an individual context). And they were mostly seen as interesting people. They can only be understood in different ways (according to the views of the Evenki), their (Russian) accent is different ('non-local').

Interethnic conflicts between Evenki and Buryats west of Lake Baikal have a long history. While this attitude becomes evident among the adults, the youth do not make any distinctions within their generation: they did not identify any young Buryat people in the village. Nobody identified themselves as 'Buryat' among the youth. However, the Evenki young people sometimes use the term 'Buryat' to mark the difference between the outside world and themselves.

The solidarity among themselves (in this age cohort) occurs on a higher level than the distinction on the basis of ethnicity. Socialization is always the most important factor in the discussion of ethnic identity, so ethnicity appears less important. There are other forms of solidarity, which are more important, and occur among groups defined by passport data, such as, for example, solidarity among members of an age cohort.

\section{CONCLUSION}

This article aimed to discuss the social life in an Evenki village in South Siberia as reflected in the opinions of the youth, and focuses on two or three questions which are important to them. I would have liked to juxtapose their opinions with the life experiences of adults, and to help deconstruct the (outsider/ Russian) stereotypes about the life of Evenki and other 'small peoples of the North' on the basis of my observations in a local community. Since the collapse of the Soviet regime there have been no spectacular changes from the point of view of Evenki, even though Upper-Lena Evenki have increasingly started to communicate with the outside world. While the mainstream (passive) attitude towards the Evenki has not changed (it is similar to that of the former Soviet system) and the possibilities for the Evenki have not significantly increased, as individuals they more expressly and actively wish to speak out on social issues 
concerning them and their own (private) lives. ${ }^{32}$ And these questions particularly concern youth (the children of adult Evenki), because they are, first and foremost, relevant for the future. It is not the new intelligentsia who gets into the jobs of bureaucracy, but the young Evenki who get practice in decisionmaking. In the spring of 2003 I witnessed the "first" steps of this process.

\section{ACKNOWLEDGEMENTS}

This research and related fieldwork were supported by the Siberian Studies Centre of Max Planck Institute for Social Anthropology (Halle/Saale, Germany) and Eötvös grant (Budapest, Hungary). Furthermore, I would like to thank László Bánszegi for helping me with English translation of this paper, and the Joachim Otto Habeck for his useful comments.

\section{NOTES}

1 The title is in accordance with Hilary Pilkington's statement, "if, in the Soviet period, youth symbolized the bright future which young people themselves would build and live in, then in post-Soviet Russia youth symbolizes the depths to which the country has fallen. The moral state of young women (defined only in terms of their reproductive role) symbolizes the degradation of the country as a whole..." (Pilkington 1994: 4).

${ }^{2}$ I chose this place as my fieldsite to make comparative fieldwork between the Evenki and Buryats because it is the southernmost compact Evenki population, at the border of the steppe and taiga, and has traditional connection with the neighbouring Buryat populations, among whom I had conducted extended fieldwork in 2000. During this fieldwork I had known the Buryat-Evenki interethnic connection from the point of view of the taiga and steppe Buryats.

3 See Pilkington 1996: "It is not accidently the trend researching the Russian society from gender aspect, because it was crucial point in the USSR to create new stereotypes by the new state power after the October Revolution, which sometimes later can become optional identities in practice."

Pilkington mentioned that "the reduction of femininity to the combination of the social roles of mother and worker as well as the degradation of the 'male' public sphere to one of ritual and collective subordination in the Soviet period has led to the popular appeal of 'traditional' (i.e. pre-revolutionary) gender roles and identities associated with notions of the 'strong man' and the strong mother figure but the 'weak woman'." (Pilkington 1994: 42)

4 According to Turuntsev, "the influence of the social background and socio-economic status is a difficult question to study in cross-cultural research. Specifically, when the structures of the societies differ as much as they do in Finland and Russia one 
standard which could be applied to the former Socialist country and the Western industrial country does not exist."(Turuntsev 1995; see also Kasurinen 2000: 123)

5 See also theoretical discussion in Elias 1978: 26 and Heller 1984. Vesa Puuronen and Helena Kasurinen have noted that "in Russia the contents and meaning of everyday life are not necessarily based on action and activites (or consumption) but [...] on personal relations and emotions." (Puuronen \& Kasurinen 2000: 31)

${ }^{6}$ Everything is Still before You. Being Young in Siberia. Siberian Studies Centre, Max Planck Institute for Social Anthropology, Halle/Saale,15-17 November 2003.

7 Generation P in the Tundra. Tartu, 8-10 October 2004.

8 Vesa Puuronen and Helena Kasurinen have noted that "significant problems arose when we attempted to classify the traditional Russian intelligentsia in terms of Finnish (Western) classification system, and another problematic group in Russian society is made up of high level administrations, who maintain a specific status of their own." (Puuronen \& Kasurinen 2000: 32)

9 On temporal perspective see also Kasurinen 2000: 122.

${ }^{10}$ Hilary Pilkington has written about the importance of ethnographic fieldwork, arguing that it "often reveals shifts and changes in the subjects' relation to specific elements of youth cultural practice (dance, dress, fighting, etc.), it is thus crucial to the project of understanding how dominant codes are ruptured and new, previously subordinate may become dominant." (Pilkington 1994: 41).

${ }^{11}$ See Nurmi 1989: "When the adolescents can freely list their hopes and fears, the density of the expectations can be studied which means the absolute number of events or plans or fears are described." See also Kasurinen (2000: 124).

12 "As shown in many of the Russian studies of the 1990s, the hierarchy of value orientations of young people undergoes a change in the role and meaning of a personality as an active and independent actor" (Molodezh' Rossii 1993: 170; Sinisalo, Shvets \& Rusanova 2000: 88).

13 "The classification of these strands of practice not as groups but as strategies indicates that they are not only socially located in the past (in the social cleveages of the Soviet modernity), but reflect young people's negotiations of the present and imaginings of the future [...] young people's horizon - their ability to travel and see beyond the locality [...]" (Pilkington 2003: 224) "while at the same time peripheralizing them in their wider value system." (Pilkington 2003: 226)

14 This closed world is in contrast with phrases like 'tradition'/traditional', 'modern' and 'civilization'. Hilary Pilkington has written that "while youth at the 'core' is understood to be engaged in postmodern 'being', youth on the periphery is described as being engaged with the global cultural economy in a process of 'becoming' " (Pilkington 2003: 16). Joachim Otto Habeck, coordinator of our group in Halle thinks that we need to look at the contrast between 'traditional' and 'modern' as something constructed (or constructed to a large extent).

${ }^{15}$ Youth did not discuss spiritual ideas, and shamanism was hardly mentioned in the responses of the the older respondents. It is in accordance with Pentti Sinisalo's, 
Larissa Shvets' and Valentina Rusanova's results of their comparative study between Karelian youth in Russia and Finland, "there was a high rating of such values as freedom, honesty, love, and peace, and a very low rating of religious salvation, irrespective of the age group or gender." (Sinisalo, Shvets \& Rusanova 2000: 89). Another uninteresting topic for the youth was the most tragic event in the history of the village: in 1965, the Evenki liquidated reindeer-herding owing to external pressure (leaders from outside the community refused to pay wages to reindeer herders; since that time, most of the local Evenki had no practical experience with reindeer). Regardless of that, these topics were relatively important for the adults and the outsiders, but none of the interviewed youth paid attention to these. These different approaches could be explained by the different knowledge of the different generations or the later socalization.

16 This scenario happened among the Central-Irkutsk Evenki under the lead of B. E. Petri. In his dissertation Joachim Otto Habeck showed that this was a long-term process among Komi reindeer herders: it did not actually start in 1930 but rather in the mid-1930s. The process went on at least until the 1960s [as was the case among the Western Buryats], if not until the 1980s in EAO (Evenk Autonomous Republic), at least in Sakha (Yakutia).

${ }^{17}$ Companionship forms a significant part of the Evenki ethnicity. Besides the poka$z u k h a$ (Russian for something done for show, the boasting about nonexistent achievements) for strangers, companionship is the potential way for the Evenki to behave among themselves. In other words, there are two available kinship structures of social organization for the Evenki. One is a patrilinear hierarchical clan structure, which is in accordance with the neighbouring cattle-breeding Buryat society. The other is the social organization of a hunter society, which is based on the complementary and symmetrical behaviour of the Evenki individuals, who are responsible for each other, which does not rule out their becoming each other's competitors (Sántha \& Safonova: forthcoming).

18 This formulation is relatively often used in this article to denote 'non-local', 'located outside the village and the territory of obschina', i.e. in the Kachug District, in Irkutsk Oblast, in Russia, and elsewhere in the world, except this Evenki village in South Siberia.

19 "In contrast normal youth located in cultural practice locally, and territorially around home (dvor) or place of study - rather than translocally and symbolically (through style or music). In sharp contrast to the progressive, in their communicative practice normals valued most highly not new information, diverse people, and a sense of perpetual motion, but the security generated by a stable, territorially rooted friendship network." (Pilkington 2003: 224).

${ }^{20}$ On this point of view see also Ventsel (2005) and Ziker (2003).

21 The fourth (4) outside interest became evident in 1995, at the time of the negative boom of the state ethnic policy regarding the 'small peoples of the North'. On the request of two neighbouring minor Evenki villages, the district administration closed the ethnic (Evenki) boarding school in the village, and moved it to the neighbouring Russian village. This way the authorities largely held on to the state finances allocated to support the education of the Evenki children. In 2003, the Evenki kindergar- 
ten was closed in the village and since then no scheduled aeroplanes and helicopters flew to the village.

${ }^{22}$ The locals do not explicitly express this in quite this manner.

${ }^{23}$ Instead of using money, the villagers received a telegram by the district administration so that they could get a document with a stamp about their pension or child care benefits. With this document they could make purchases in the local store for the amount written on the stamped piece of paper.

${ }^{24}$ People have already abandoned the Evenki language in the village where the research was carried out; it is not for everybody and the few people who speak it, do not do so all the time.

${ }^{25}$ According to another interpretation, he froze himself on purpose because he believed that he could warm up in the next hunting cabin, which, unfortunately was closed by the owner to protect the property from vandalism.

${ }^{26}$ Almost all the teachers in the village are women and ethnic Russians. The only exception is a male teacher who also has a Russian ethnic background and whose wife is the only female hunter in the village.

27 "Ideological domain is the most predictive status for males, while status in sexualinterpersonal domains is the most predictive for females" (Bilsker, Schniedel \& Marcia 1988: 231-236; Nummenmaa \& Puuronen 2000: 109).

${ }^{28}$ The anthropologist, too, can become only a guest, when living in the village.

${ }^{29}$ Which stands for "the small group, the community of outsiders within the village".

${ }^{30}$ Adults who have personal experiences with Yakuts use this term to determine those living in cities of mixed ethnic background (the 'Sakhalars'). This term is synonymous with the term metis used by the Evenki people, "Sakhalars are metis people".

31 The boarding school in this Evenki village was closed in 1995.

${ }^{32}$ Pentti Sinisalo, Larissa Shvets and Valentina Rusanova have mentioned that "the question is whether this directly depends on the transition period, which has raised private life and primary social groups (family, personal relations) to the centre of life goals. [...]While the core of the 'Soviet consciousness' was the dominance of collectivist and supra-individual values, today virtually all age groups, especially the young, exhibit an orientation towards private life priorities and the care of one's own material and spiritual wellbeing." (Sinisalo, Shvets \& Rusanova 2000: 88).

\section{REFERENCES}

Bilsker, Dan; Schiedel Don G. \& Marcia, James E. 1988. Sex Differences in Identity Status. Sex Roles? Vol. 18, No. 3/4, pp. 231-236.

Elias, Norbert 1978. Zum Begriff des Alltags'. In: K. Hammerich \& M. Klein (eds.) Materialien zur Soziologie des Alltags. Kölner Zeitschrift für Soziologie und Sozialpsychologie, Sonderheft 20. 
Habeck, Joachim Otto 2006. What it Means to Be a Herdsman. The Practice and Image of Reindeer Husbandry among the Komi of Northern Russia. Halle Studies in the Anthropology of Eurasia. Vol. 5. Berlin \& Halle: LIT Verlag.

Heller, Ágnes 1984. Everyday Life. London: Routledge \& Kegan Paul.

Kasurinen, Helena 2000. Introduction to Part IV: Constructing a Personal Future. In: V. Puuronen et al. (eds.) Youth in a Changing Karelia: A Comparative Study of Everyday Life, Future Orientations, and Political Culture of Youth in North-West Russia and Eastern Finland. Aldershot, Burlington: Ashgate, pp. 121-126.

Khlinovskaya-Rockhill, Elena 2003. Family Discontinuity and 'Social Orphanhood' in the Russian Far East: Children in Residential Care Institutions. Unpublished $\mathrm{PHD}$ dissertation. Cambridge: University of Cambridge.

Nummenmaa, Anna Raija \& Sinisalo, Pentti 2000. Gender Differences in Identity Development. In: V. Puuronen et al. (eds.) Youth in a Changing Karelia: A Comparative Study of Everyday Life, Future Orientations, and Political Culture of Youth in North-West Russia and Eastern Finland. Aldershot, Burlington: Ashgate, pp. 107-120.

Nurmi, Jari-Erik 1989. Adolescents' Orientation to the Future. Development Interests and Plans, and Related Attributions and Effects, in the Life-Span Context. Societas Scientiarium Fennica. Commentationes Scientiarium Socialium 39. Helsinki.

Pilkington, Hilary 1994. Russia's Youth and its Culture. London \& New York: Routledge. Pilkington, Hilary (ed.) 1996. Gender, Generation and Identity in Contemporary Russia. London \& New York: Routledge.

Pilkington, Hilary; Omel'chenko, Elena; Flynn, Moya; Bliudina, Ul'iana \&Starkova, Elena (eds.) 2003. Looking West? Cultural Globalization and Russian Youth Culture. Pennsylvania: Pennsylvania State University Press.

Puuronen et al. $=$ Puuronen, Vesa; Sinisalo, Pentti; Miljukova, Irina \& Shvets, Larissa (eds.) 2000. Youth in a Changing Karelia: A Comparative Study of Everyday Life, Future Orientations, and Political Culture of Youth in North-West Russia and Eastern Finland. Aldershot, Burlington: Ashgate.

Puuronen, Vesa \& Kasurinen, Helena 2000. The Everyday Life of Young People in Karelia in the Mid-1990s. In: V. Puuronen et al. (eds.) Youth in a Changing Karelia: A Comparative Study of Everyday Life, Future Orientations, and Political Culture of Youth in North-West Russia and Eastern Finland. Aldershot, Burlington: Ashgate, pp. 29-57.

Riordan, Jim (ed.) 1989. Soviet Youth Culture. Bloomington \& Indianapolis: Indiana University Press.

Sántha, István \& Safonova, Tatiana (forthcoming). Ethos of Evenki People in Eastern Buryatia: Companionship and Pokazukha. Working Papers of Max Planck Institute for Social Anthropology.

Semashko, Irina M. \& Sedlovskaia, Anna N. (eds.) 1999. Muzhchina i zhenshchina $v$ sovremennom mire: meniaiushchiesia roli i obrazy. [Man and Woman in Today's World: Shifting Roles and Images.] Moskva: Institut Etnologii i Antropologii im. Miklukho-Maklaia, RAN.

Molodezh'Rossii: tendentsii i perspektivy. 1993. [The Young People of Russia: Tendencies and Prospects]. Moscow: Molodaia Gvardiia, p. 170. 
Sinisalo, Pentti; Shvets, Larissa \& Rusanova, Valentina 2000. Value Orientations of Russian and Finnish Young People. In:V. Puuronen et al. (eds.) Youth in a Changing Karelia: A Comparative Study of Everyday Life, Future Orientations, and Political Culture of Youth in North-West Russia and Eastern Finland.Aldershot, Burlington: Ashgate, pp. 74-91.

Ssorin-Chaikov, Nikolai 2003. The Social Life of the State in Subarctic Siberia. Stanford: Stanford University Press.

Trommsdorff, Gisela 1994. Future Time Perspective and Control Orientation: Social Conditions and Consequences. In: Z. Zaleski (ed.), Psychology of Future Orientation, Lublin: Towarzystwo Naukowe KUL, pp. 39-62.

Turuntsev, Evgeni 1995. The Transforming Class Structure in Russia: Between Real Socialism and Modernity. Idäntutkimus (The Finnish Review of East European Studies). Vol. 2, No. 4, pp. 5-18.

Ventsel, Aimar 2005. Reindeer, Rodina and Reciprocity: Kinship and Property Relations in a Siberian Village. Münster: LIT Verlag

Pushkareva, Natalia L. 2003. Zhenshchina i muzhchina $v$ svete medico-antropologicheskikh dannikh. Chast' IV. [Woman and Man in the Context of Medical-Anthropological Data. Part 4.] Moskva: Institut Etnologii i Antropologii im. Miklukho-Maklaia, RAN.

Ziker, John P. 2002. Peoples of the Tundra. Northern Siberians in the Post-Communist Transition. Illinois: Waveland Press.

Ziker, John P. 2003. Kinship and Friendship in the Taimyr Autonomous Region, Northern Russia. Sozialersinn. Vol. 1, pp. 59-80.

Williams, Christopher \& Sfikas, Tanasis D. (eds.) 1999. Ethnicity and Nationalism in Russia, the CIS and the Baltic States. Aldershot: Ashgate. 